\title{
Intestinal vasculitis and lithium carbonate-associated diarrhoea
}

\author{
S. R. CANNON \\ M.A., M.B., F.R.C.S. \\ Department of Surgical Studies, Middlesex Hospital, London W.1.
}

\begin{abstract}
Summary
A 57-year-old male manic depressive patient is described who presented as an 'acute abdomen' whilst receiving treatment with lithium carbonate. Small bowel resection was performed, the histopathology of which revealed local vasculitic changes with thrombosis and subsequent infarction of the ileal wall. The possible aetiological role of lithium in this vasculitis is discussed.
\end{abstract}

\section{Introduction}

Lithium carbonate is now frequently used in the treatment of both unipolar and bipolar manic depressive states. It is generally thought that the adverse reactions of this drug are associated with plasma levels above the therapeutic range of $0.8-1.2 \mathrm{mmol} /$ litre, but they may also be associated with long-term usage of the medication within the recommended plasma concentrations. (Persson, 1977). The effect of lithium on the thyroid (Schou et al., 1968a) and on alterations in serum calcium and magnesium concentrations, may occur with totally acceptable plasma concentrations of the drug (Carman et al., 1974). Similarly, reversible electrocardiographic $T$-wave changes and arrhythmias can occur without a plasma concentration greater than $1.5 \mathrm{mmol} /$ litre (Jaffe, 1977). Nephrogenic diabetes insipidus has also been noted in patients with therapeutic lithium levels, the mechanism involved being thought to be an antagonism of the action of antidiuretic hormone on adenylcyclase. (Editorial, 1977). Diarrhoea is perhaps the most commonly reported side effect of lithium and has been classified into two types. Firstly, a mild variety associated with acceptable serum levels and secondly, a severe form usually associated with levels greater than $2.0 \mathrm{mmol} /$ litre (Schou, Amdisen and Thomsen, 1968b).

The following case history is of a patient who experienced severe episodic diarrhoea with acceptable serum levels before presentation as a surgical emergency.

\section{Case report}

In November 1978, a 57-year-old Caucasian presented to the Casualty Department complaining of vomiting, colicky central abdominal pain and distension. He had not undergone any previous abdominal surgery but suffered from mild ischaemic heartdisease. He was a regular attender at the psychiatric department of the hospital where he had been diagnosed in 1964 as a manic depressive. He had been treated since that time with a number of psychotropic agents and in 1975 lithium was introduced. In 1978 he was taking in addition to lithium, amitriptyline, chlordiazepoxide, cyclopenthiazide and oxprenolol. On lithium carbonate, he had suffered from episodic severe diarrhoea which did not alter despite alterations in dosage, and serum levels of lithium were consistently below $1.5 \mathrm{mmol} /$ litre. Before his presentation on this occasion he had experienced severe diarrhoea.

On examination he was not shocked and only minimally fluid depleted. The abdomen was uniformly distended with increased bowel sounds. There was minimal tenderness in the right iliac fossa. $\mathrm{He}$ was apyrexial.

$\mathrm{X}$-rays confirmed incomplete small bowel obstruction at the level of the distal ileum. Full blood count, blood urea and electrolyte estimations were within normal limits. The patient was admitted and treated initially with intestinal decompression and intravenous fluid replacement. Twenty-four hours following admission, however, he began to experience moderate background pain in the right iliac fossa and examination on this occasion revealed marked peritonism. He was therefore subjected to laparotomy. At operation the terminal ileum had an appearance grossly suggestive of regional ileitis and a local resection with ileo-colic anastomosis was carried out. Histological examination of the specimen (Figs. 1, 2) revealed the primary lesion to be local vasculitis with consequent thrombosis and infarction of a small portion of the ileal wall. No evidence of granulomatous ileitis was found in the resected specimen. 


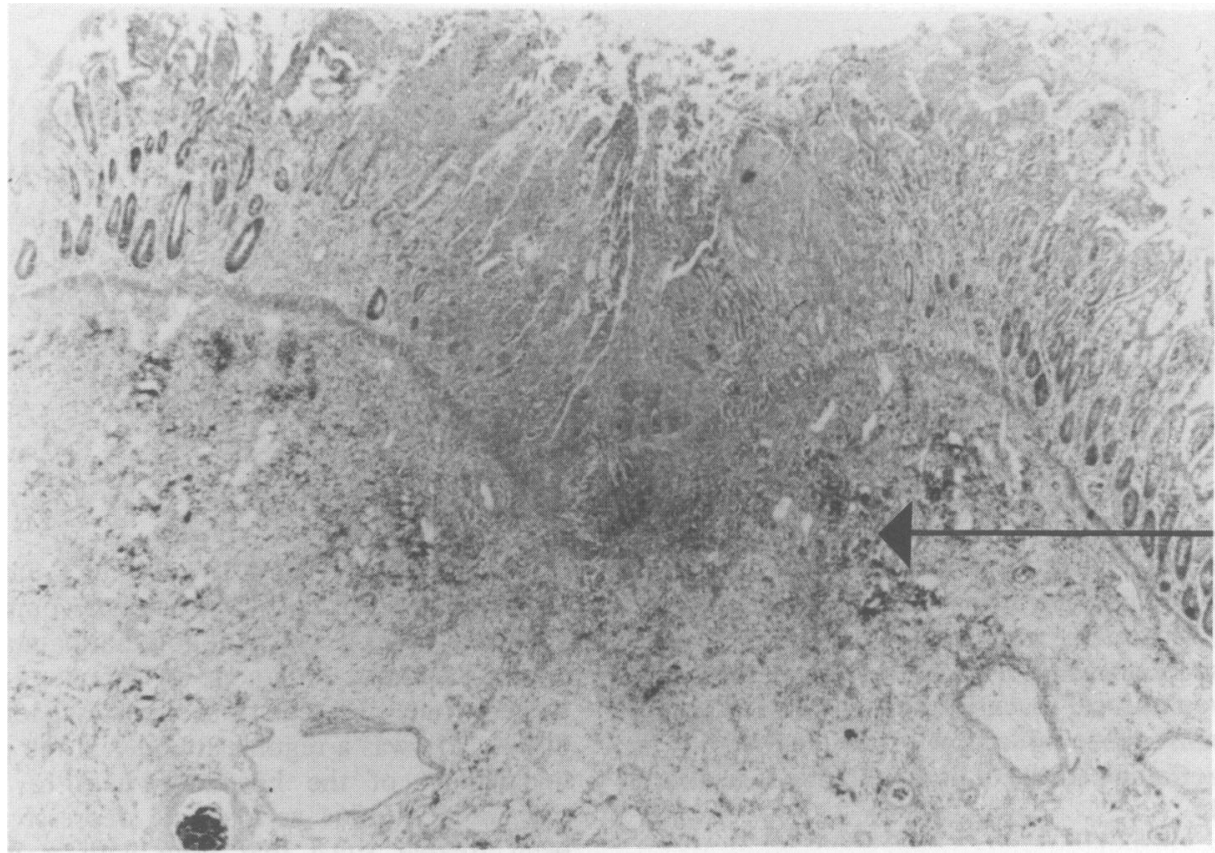

Fig. 1. Illustrates the localization of the response to predominantly the sub-mucosal and muscular layers, together with the absence of any granuloma formation $(\mathrm{HE}, \times 25)$.

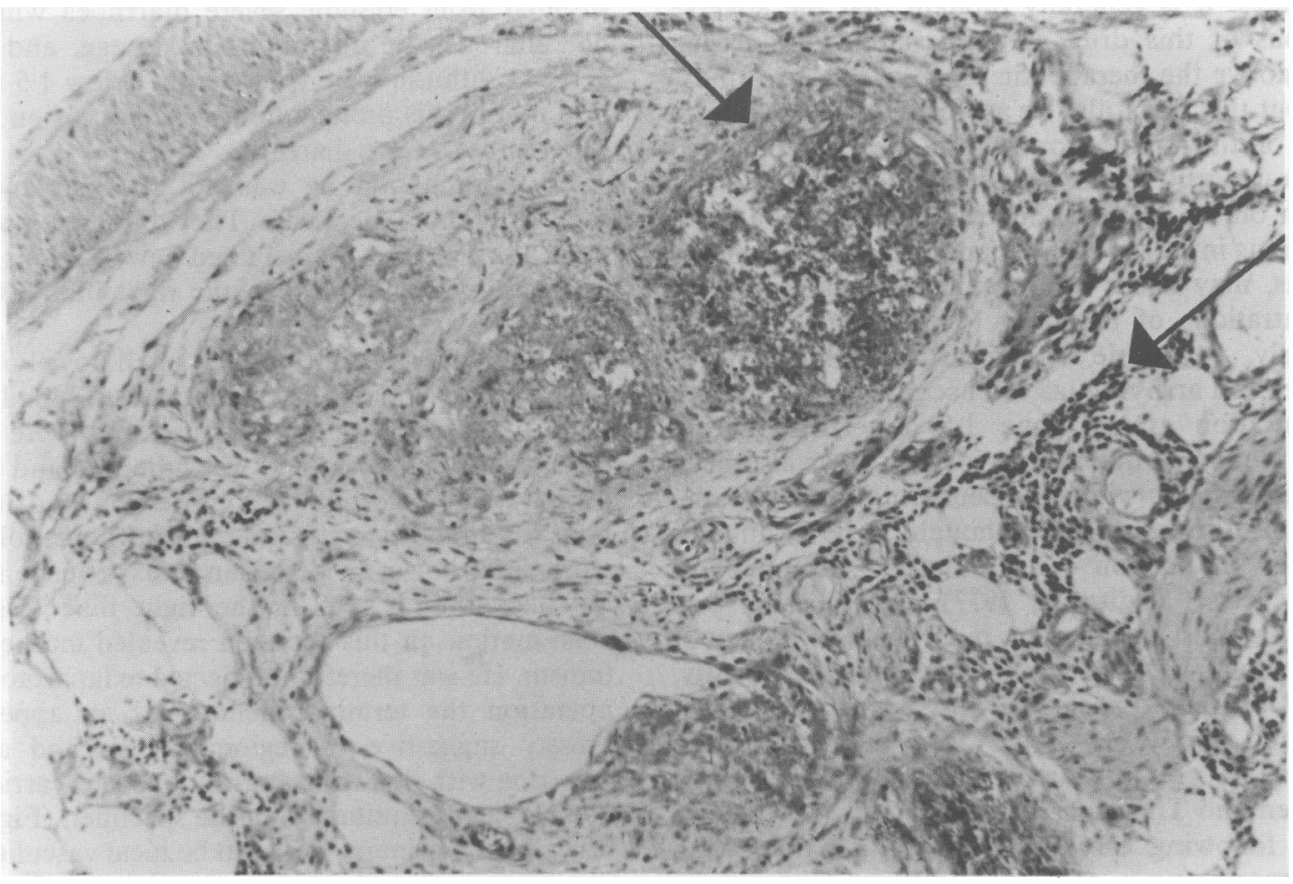

FIG. 2. Illustrates thrombotic changes in an arteriole with localization of an acute inflammatory response in the perivascular region (HE, $x$ 200). 
The patient made an uneventful postoperative recovery and was not restarted on lithium. At followup he has had no further diarrhoea and remains well, apart from depression.

\section{Discussion}

There has been one previous report of severe diarrhoea associated with therapeutic serum lithium levels (Varsamis and Wand, 1972). In that case the patient, a previously well male, also developed an acute abdomen and an ileal resection was performed. The histology at the time was thought to be regional ileitis but his diarrhoea did not disappear until lithium carbonate was discontinued. Sadly both he, and his histology have been lost to further scrutiny.

In the present case the histology was thought to be local vasculitis as distinct from regional ileitis and its aetiology remains conjectural. The patient's diarrhoea commenced in association with the introduction of lithium to his therapeutic regime and it is recognised that combination with other psychotropic agents may increase its toxicity (Guy-Edwards, 1977). This then may have been the sole aetiology of the diarrhoea but the finding of a distinct enteral pathology which may be associated with the use of lithium carbonate requires further elucidation. Certainly any patient presenting with severe diarrhoea whilst taking this drug and whose serum levels are in the acceptable range, warrants further gastroenterological investigation.

\section{References}

Carman, J.S., Post, R.M., Teplitz, T.A. \& Goodwin, F.K. (1974) Divalent cations in predicting antidepressant response to lithium. Lancet, ii, 1454.

EDITORIAL (1977) Adverse effects of lithium treatment. British Medical Journal, 2, 346.

GUY-EDWARDS, J. (1977) Unwanted effects of psychotropic drugs. Practitioner, 219, 231.

JAFFE, C.M. (1977) First degree atrioventricular block during lithium carbonate therapy. American Journal of Psychiatry, 134, 88.

Persson, G. (1977) Lithium side effects in relation to dose and to levels and gradients of lithium in plasma. Acta psychiatrica scandinavica, 55, 208.

Schou, M., Amdisen, A., Jensen, S.E. \& Olsen, T. (1968a) Occurence of goitre during lithium treatment. British Medical Journal, 3, 710.

SChou, M., Amdisen, A. \& Thomsen, K. (1968b) Clinical and experimental observations concerning the absorption and elimination of lithium and on lithium poisoning. Acta psychiatrica scandinavica, 203 (Suppl.), 153.

VARSAMIS, J. \& WAND, R.E. (1972) Severe diarrhoea associated with lithium carbonate therapy in regional ileitis. Lancet, ii, 1322. 